\title{
A serenidade por que elas anseiam nos intervalos da respiração em A Morte e a Donzela, de Elfriede Jelinek
}

ANABELA MENDES

The present essay deals with the rhizomatic relations that underlie the dramatic writing of Elfriede Jelinek in the 2004 work Der Tod und das Mädchen (The Death and the Maiden), and how these links weave a larger discourse on the questioning that life recreates against death. In this context, some of her themes of election will be revisited, for example, the permanent political commitment, under which public and private are generated and grounded, which is disjointed between man and woman, reconfiguring life as a myth. This five-part series on princesses is still an attempt to submerge "negativity" and to bring about "the inspirational weariness" of South Korean philosopher Byung-Chul Han.

eles estão a morrer de todas as maneiras mas diga-me: não há apenas uma só maneira: a maneira cega?

Herberto Helder, Poemas Canhotos

PEREGRINAC̣ÃO

«Então vocês fazem dinheiro com os mortos?», eis como um jovem zambiano, guia de profissão, se perguntava incrédulo, a não muitos metros da sua aldeia natal, e em conversa com viajantes europeus, como era possível que uma galerista incluída nesse grupo, cujo espaço de trabalho se situava na rue des Beaux Arts em Paris, fosse capaz de fazer negócio com obras de Picasso, Monet e outros artistas plásticos mais recentes, se os referidos criadores estavam mortos?

Segundo ele, os mortos são para ser deixados em descanso até ao fim dos tempos. O negócio, qualquer negócio, só se faz entre os vivos, pois 
estes podem sempre defender-se e encontrar a melhor solução para aquilo que procuram e desejam alcançar. Aos mortos só se deve pedir que olhem pelos vivos, iluminando-lhes de longe o caminho e inspirando neles as boas oportunidades de vida.

$\mathrm{N}$. queria saber como é que a galerista parisiense fazia para obter a voz e o assentimento dos artistas mortos ao negociar as obras em leilão.

A perplexidade da jovem senhora não era inferior à do zambiano, se bem que evidenciando ser de sinal contrário. Afinal, tratava-se de um choque entre culturas e tradições, tratava-se, aliás, de uma resistência mental em que a memória e a experiência de cada um não encontravam argumento e resposta plausíveis que pudessem oferecer a ambos um modo de entendimento comum para aquilo que os dois interlocutores defendiam com legitimidade. N.e S. deixaram em paz os mortos, sabendo ambos que estes podem regressar sempre a qualquer momento mesmo que seja com diferentes funções.

Os verdadeiros mortos, e não os mortos-vivos, desprendem-se de nós para connosco se voltarem a religar de outra maneira. O que sentimos é a saudade do corpo e das características dele. Aquilo que perdemos em termos físicos, mas que podemos incorporar num amor mais profundo por ele e por nós, é o que se relaciona com o caminho que com os mortos fazemos juntos em vida. Assim, o nosso estado de espírito sairá fortalecido por essas vivências comuns, às quais damos agora nova oportunidade de releitura e sentimento. Não podemos deixar que aquilo que é o dever ser e se conforma como ajustamento a uma realidade, ela mesma pautada por regras que todos preferimos cumprir a pôr em causa, possa impedir-nos de que aquilo que nos move não se venha a sobrepor à atitude que referencia um não poder, um não ser capaz de questionar o que se apresenta como estabelecido. A nossa pacificação com os mortos acontece normalmente sob um novo estado para o qual os mortos também contribuem. Os mortos fortalecem-nos mesmo quando disso não nos apercebemos. Os mortos são a esperança da nossa imperecibilidade de vida, a privada, a pública e a da espécie. Os meus mortos, os mortos de cada um de nós, deixam-nos uma missão: sermos deles continuadores.

EXPEDIÇÕES

Em Der Tod und Das Mädchen I - V Prinzessinnendramen (A Morte e a Donzela I a V Dramas de Princesas) e em Die Prinzessin in der Unterwelt 
(A Princesa no Mundo Inferior), Elfriede Jelinek cria uma ampla e diversificada proposta para dispositivo cénico composta por cinco dramatículos (alguns mais extensos do que outros) e um texto formalmente à parte mas que representa uma espécie de fecho de percurso. ${ }^{1}$

A autora socorre-se de uma multiplicidade de fontes inspiradoras, que podemos considerar um quebra-cabeças do ponto de vista hermenêutico, mas que nos alerta para o facto de que o passado, qualquer passado, mesmo antes de ser um espaço em que se pára e a que nem sempre regressamos com verdadeira consciência, é um lugar onde talvez possamos estar sem regresso algum, na medida em que com ou sem história, com ou sem memória de nitidez aditiva e cumulativa somos capazes de recriar a resistência da vida à morte, tal como acontece com os textos de Elfriede Jelinek, em particular, Os Dramas de Princesas.

A textualidade jelinekiana cria connosco uma proximidade-distância de grande exigência e singularidade, nem sempre sendo consubstanciada pelos resultados interpretativos que possamos alcançar. Depois de nos termos disseminado por dentro da sua escrita, sentimo-nos muitas vezes atópicos dentro dela, como se estivéssemos fora do lugar, ou como se a autora nos quisesse manter em perpétuo deslocamento. Reconhecemo-nos em certas temáticas por ela trabalhadas, mais concretamente, a vontade de um comprometimento político, público e privado, sobre as relações entre homem e mulher; a desestabilização de estruturas patriarcais; a questionação da mitologização da vida, por exemplo, através da revisitação a contos maravilhosos, mas também no curto-circuito da moda e da publicidade. Estabelecemos com algumas das suas figuras de eleição um compromisso distendido no tempo e no espaço que sobre nós carregamos não como um peso óbvio, mas como um território a desbravar (o caso das vidas e obras de escritoras como Sylvia Plath, Ingeborg Bachmann, Marlen Haushofer que constituem o subsolo da peça $\mathrm{v}$ do conjunto, com o título A Parede).

1 Com a obra Macht nichts. Eine kleine Trilogie des Todes (2002) (Hamburgo, Rowohlt), Elfriede Jelinek prossegue a publicação da série de peças dedicadas a princesas que viria a concluir e a dar à estampa na sua versão final em 2004. Esta edição sucede a anterior publicação de 1999, na mesma editora, e à publicação em 2000 e 2002 respectivamente de Das Lebewohl. 3 kl. Dramen (Berlim, Berlin Verlag) e In den Alpen. Drei Dramen (Berlim, Berlin Verlag). Tratava-se então dos três primeiros dramas dedicados a Schneewittchen (Branca de Neve), Dornröschen (Bela Adormecida) e Rosamunde (Rosamunda). As peças iv e v, designadas por Jackie e Die Wand (A Parede), estão presentes na edição de 2004. Refira-se a propósito que Die Prinzessin in der Unterwelt (A Princesa no Mundo Inferior), último texto da sequência e dedicado a Diana Spencer, foi pela primeira vez publicada no periódico Die Zeit a 2 de Janeiro de 1998. A edição a que se fará referência neste ensaio é a seguinte: Elfriede Jelinek (3) (2012), Der Tod und das Mädchen I-V Prinzessinnendramen, Berlim, Bloomsbury Verlag. A tradução de passagens citadas desta obra é da minha inteira responsabilidade. 
Somos, porém, catapultados por este conjunto polifónico, diria mesmo, literalmente abraçados e atrofiados pela tentacularidade da morte e suas variações. Esta atravessa com incontida saturação todo o construir de parcelas autónomas e conjunturais de uma dramaturgia de oposição entre ser belo e ser verdadeiro, donde a verdade última é já aquela que impiedosa nos espreita e de nós se apropria. Sendo a morte um falso fiel de balança nas nossas vidas, porque connosco mantém uma inequívoca relação de poder e de dominação, sentimo-nos constrangidos perante ela ao desaprendermos a capacidade de morrer em nós e no outro. Deste modo o confronto com a morte desdobra-se em sucessivas tentativas de querermos manter em aberto aquilo que tem de ser concluído.

As existências contadas e representadas destas princesas, geradas em diversos tempos e lugares, transformam-se assim em discurso argumentativo, monologado ou em contracena, como meio de salvaguardar a todo o preço a positividade da vida descontínua (Han, 2012:33), em detrimento da sua negatividade. É justamente no âmbito desta que se consagra a vida verdadeira, aquela que se manifesta através da contradição e na qual se faz jus à capacidade vital.

Não é fácil para estas princesas, no estrito espaço ficcional e referencial, nem mesmo para nós, como leitores e espectadores da obra de Elfriede Jelinek, saber que acedemos a um universo de sobreviventes cuja liberdade exequível transporta em si mesma a inequívoca condenação. As princesas estão demasiado mortas para viver e demasiado vivas para morrer. Nelas o que perdura é a condição de mortas-vivas, e é dessa capacidade desprovida de fim que se alimenta o imaginário de cada um de nós.

A Morte e a Donzela, o título geral da obra, é para isto que remete, não deixando ao leitor qualquer dúvida sobre o assunto principal em questão. Subjacente às inúmeras recorrências e representações de que a Morte se faz eco ao longo dos tempos, como afronta aos vivos mas também como tentativa de que nos pacifiquemos perante ela, encontramos nestes textos de Jelinek, em correspondentes variações, aquilo a que diversas vezes aludem as personagens, masculinas e femininas, e que corresponde à necessidade de apanhar viva a presa-Mulher:

Não reparaste em mim, preferiste descrever a pujança da minha insignificância. Porque perseguias um outro significado! Ora aqui tens! A corça és tu, grande mulher! A presa és tu! Sim, sim, agarra-te bem, eu estou disposto a segurar-te. (1. a réplica de Fulvio, dactiloscrito, A Morte e a Donzela III, p. 6) 
Ou umas páginas adiante:

Partimos como conquistadores e regressamos como conquistadores, mas voltamos outra vez a partir. Para regressarmos outra vez como nós próprios. Felizes, saltamos então com a nossa presa em direcção à loja mais próxima para fazer um vídeo com ela. (3. ${ }^{a}$ réplica de Fulvio, dactiloscrito, A Morte e a Donzela III, p. 10)

A Morte-caçadora instrumentaliza, mais pelo discurso do que pela acção (esta é quase sempre cirúrgica e letal), aquilo que afinal parece imprevisível, embora avassalador, e que se manifesta naquele sentimento que se apodera das personagens femininas quando não encontram nem sombra de vestígio da sua interioridade fora delas, nem reconhecem no mundo aquilo em que ele se tornou: uma previsibilidade hostil, um retorno desprovido de eternidade, o medo de dizer sim, a estupefacção perante o êxtase como sujeita a programação apenas espoletada por um estímulo.

Possuidoras desta consciência, as personagens femininas desta obra de Jelinek resistem a cada acto de descodificação literária e cénica como se estivessem sempre a fazer a apologia do «estar de fora», como seres inactuais. Também esse distanciamento contribui para que nelas vejamos a hibridez dos seus estados existenciais que as esgotam e deprimem. A procura de si mesmas faz-se na inquirição que a elas próprias propõem e que se consuma no desvendar de enigmas que o discurso e a contracena implicam e desencadeiam. Resulta daí que uma tal postura se torna falível pela exigência da argumentação e contra-argumentação, o que estabelece também para intérpretes e receptores um horizonte de resistência fundado no exercício inabitual de reservar mais espaço ao pensamento filosófico do que ao dramatúrgico.

A apropriação das imagens e ideias propostas pela textualidade jelinekiana reconfigura em nós um sentimento de pertença e não-pertença a uma sociedade actual que de si mesma está cansada, porque se deixa sufocar por excesso, pelo desperdício, pela volatilidade das coisas que se sobrepõem à não-admissão do risco essencial que significa viver. A questão do hibridismo, que fundamenta o debate sobre o morto-vivo, neste caso as mortas-vivas, é um pressuposto que diz respeito a «atracções e temores humanos arcaicos» (Molder, 2003: 135), de que a Morte é parte essencial.

Em boa verdade, reportamo-nos a seres que, antes de entrarem no espaço da representação teatral (é esse o seu destino natural como forma 
de actualização artística), referenciam não a sua condição de mortalidade histórica e funcional, mitológica também, mas o facto de já haverem esgotado em vida (singular e colectiva) a mistura simbólica entre carne e imagem, de cuja experiência sentimental só podemos receber e recriar em simulacro. Quer isto dizer que As Princesas de Elfriede Jelinek passaram a existir outra vez porque deixaram de ter equivalente na realidade, qualquer que ele fosse, pois estão esvaziadas de qualquer confronto com o real. Torná-las presentes requer a compreensão de que é uma impossibilidade recuperar da sua intimidade e mundanidade imagens orgânicas associadas a elementos emotivos. Encená-las ou recuperá-las como interpretação artística e dramatúrgica poderá significar que, por causa delas, tenhamos de conviver de forma mais intensa com a morte que, neste caso, se dá a ver através de imagens e discurso entrelaçados que ainda transportam em si o excesso de presença. Não nos serve já o discurso pacificador e optimista de Epicuro, que em carta a Meneceu nos aconselha:

A morte, o mais aterrorizador dos males, nada é para nós, dado que enquanto existimos a morte não está connosco; mas, quando a morte chega, nós não existimos. A morte não diz respeito portanto nem aos vivos nem aos mortos, pois para os primeiros nada é, e os segundos já nada são. (apud Murcho, 2006: 43)

Trata-se, portanto, de tentarmos contrariar a estranheza e a incomodidade do confronto com a morte, tornando-a exactamente tão enfática quanto possível, de tal modo que a convivência com ela se transforme numa revelação de nós em cada coisa e não numa redução de tudo o que em nós sentimos como hostil ou indeterminado. Reforçaremos, assim, não as nossas defesas porque elas se tornam desnecessárias, mas estaremos atentos a todas as experiências em que não nos sintamos apodrecer nem por elas possamos vir a ser envenenados.

A oposição a que nos habituámos a reagir de forma dicotómica entre Vida e Morte concentra em si outros paradigmas binários como, por exemplo, a relação entre luz e trevas, ou entre aparência e essência reportadas no par: beleza e verdade. A questionação deste universo encontra nos Dramas de Princesas de Jelinek uma discursividade determinante como complementaridade gradativa de aproximação entre o escuro insondável e a verdade última em contraponto com a insondável beleza sujeita a nascer e a perecer para que se cumpram as estações da vida: 


\begin{abstract}
A verdade como um porta-fatos crivado de bonés. E depois a beleza não gosta de pôr nenhum destes chapéus para não parecer ridícula e assim se tornar inimiga de si própria. A verdade como errância do ser. Aliás, a Menina engana-se se pensa que me vê. Eu sou invisível. E caso eu fosse visível não existiria e também por isso não me poderia ver. Tanto faz se me reconhece ou não. Se calhar enganou-se ao tomar-me por uma das suas verdades só porque não me viu. Ora, eu de qualquer modo não faço parte das suas verdades! Faça-me o favor de olhar para o meu chapéu cuidadosamente antes de me não ver e, apesar disso, estar para aí a dizer-me palermices! Eu sou a morte e ponto final. A morte como a verdade última. (1. ${ }^{a}$ Réplica de O caçador, dactiloscrito de A Morte e a Donzela I, p. 3)
\end{abstract}

DESMULTIPLICAÇÕES

A Morte e a Donzela de Elfriede Jelinek congrega em si uma implícita e explícita referencialidade a um lastro artístico de séculos, quer da literatura, quer das artes plásticas, quer da música. Sob esse princípio estabelece a autora uma outra forma de relação entre presença e ausência, simbólica e alegoricamente exposta a partir da tradição cultural germânico-austríaca. São exemplo desta tessitura de transporte e movimento: o poema Der Tod und das Mädchen (A Morte e Donzela), de Matthias Claudius (1740-1815), escrito em 1774 e publicado no Göttinger Musenalmanach: Poetische Blumenlese em 1775; a Romanze «Der Vollmond strahlt auf Bergeshöh'n» («No alto da montanha a lua cheia brilha»), escrita por Wilhelmine von Chézy e enquadrada na sua peça-libreto Rosamunde, estreada em Viena no fim do ano de 1823, e para a qual Franz Schubert compôs música incidental, designada pela sigla $\mathrm{D} 797$ e constituída por abertura seguida de dez andamentos. A Romanze 3 b está integrada na peça Der Tod und Das Mädchen III (Rosamunde) de Elfriede Jelinek (Jelinek, (3) 2012: 48).

De entre as referências plásticas que mais directamente podem encontrar repercussão no contexto da vida perecente, e dentro desta nos topoi da beleza e juventude, consideramos ser o imaginário da Idade Média um período fértil: catástrofes, epidemias e carência profunda negam a todo o momento a naturalidade da morte que se apraz em exercer sobre os vivos um efeito punitivo e aterrador. Tal como hoje, será?

É devido à grande expressividade e a um sentido estimulante e inspirador que observamos, por exemplo, imagens de obras do pintor alemão 
Hans Baldung Grien (1484/5-1545), nas quais a distância face a um cenário de absolutização entre a vida e a morte nos aparece antes delineado como uma visão da Morte jocosa e matreira, cheia de ironia, que absorve no seu amplexo a aterrada e desnuda Donzela, a Mulher madura, a bíblica Eva, a consciência da passagem do tempo como uma inevitabilidade, quase sempre deixando antever a presença de um jogo erótico de dominação protagonizado na energia pura que a mostração dos rostos descobertos nos devolve, como a seguir se verá.

Com as imagens de Hans Baldung Grien, descobrimos um outro extracto de cruzamento com as Princesas de Jelinek e que consiste na versatilidade de transporte da imagem visual para o discurso dramático. O tom desabrido, mordaz e altaneiro, mas também de sedução, com que se exprimem as personagens masculinas, condiciona toda a argumentação que as personagens femininas desenvolvem, quer estejam em diálogo quer monologuem. Assim, talvez não seja difícil perceber que as protagonistas de A Morte e a Donzela se nos revelam como seres indefesos e vulneráveis, a quem são negados todos os pressupostos e premissas que lhes permitiriam reconhecer que não aceitariam a condenação daquilo que não estão em condições de mudar. Neste sentido, a fuga da morte é vivida em convulsão, como antegosto da náusea, como participação num sacrifício vigiado por alguém que não elas e que se compraz em as liquidar. Despojadas da sua essência, a que jamais é alheia a sua corporalidade, estas Princesas oscilam de modo trágico entre um interior construído crosta sobre crosta e um exterior já há muito saturado. Desfalecem os seus corpos. Emudecem as suas vozes. A morte como enlouquecimento passa a ser o seu estatuto natural. O supremo paradoxo da sua existência e não-existência é o quererem continuar a experimentar aquilo que escapa ao seu domínio, criando raízes com o que produz a sua ruína.

É nesse estado de intermediação entre o ser que foi e aquele que regressa como espectáculo que nos apercebemos de que a resistência e o fulgor das protagonistas operam nas peças uma espécie de resiliência à própria linguagem sob a qual elas procuram protecção e ao mesmo tempo sabem que as consome. Falar muito e em constância é uma forma de fazer submergir a «negatividade» (Byung-Chul Han) que as habita e aniquila. 
Elas exprimem-se com abundância, são excessivas como se lhes não fosse permitido o emudecimento, o copioso choro, o subtil suspiro.

Do meu ponto de vista, este conjunto de peças e um posfácio demonstra que as protagonistas de Elfriede Jelinek estão sempre a correr velozmente para a sua perda, porque se confrontam com os seus limites internos que as impedem de se mostrar como seres completos e únicos. Tanta agitação e actividade pensativa cansa e destrói. A extrema violência do processo reduz, mutila e suga todas as Princesas, também na sua relação com o mundo.

Independentemente destas figuras jelinekianas provirem do imaginário dos contos maravilhosos, de realidades históricas mais próximas ou longínquas da civilização e cultura ocidentais, facto é que elas protagonizam ainda, entre outras coisas, a tal perplexidade da galerista parisiense quando inquirida sobre o aproveitamento económico da arte (e as formas deste tipo de aproveitamento são infinitas). E protagonizam-no através do acto de predação operado sobre a proliferação de imagens esvaziadas de carne e espírito em que se tornaram. Esse aproveitamento é quase sempre guloso e salivante perante obra e vida de artista morto.

Tal como o artista morto que deixa de ter voz em relação à sua própria obra, as preferidas de Jelinek não têm como se desembaraçar do estigma de mortas-vivas. Aprisionadas pelo esforço da performatividade do discurso quase ininterrupto, elas desejam alcançar o não-fazer, «o cansaço inspirador $»^{2}$ (Byung-Chul Han) que as possa redimir. A sua condição e existência como realidade artística dependem da capacidade que desenvolvem, umas mais do que as outras, a partir da violência de estarem cansadas de si mesmas, de, em suma, constituírem uma coralidade de vozes que entoa uma partitura em que cada compasso é mais um degrau de uma escala de com-partilha e não de uníssono.

2 Quando se verifica o desaparecimento da alteridade, aquilo que mantém ligação e estabelece a relação entre o eu e o outro, preservando as especificidades e características de cada um, a «positividade», segundo Byung-Chul Han, toma o lugar da «negatividade», atribuindo ao positivo um espaço de disseminação do massificado (Han, 2010: 13-17).

O desaparecimento individual do «dom da escuta», segundo Byung-Chul Han, deixa de existir e com ele toda a comunidade perde também essa capacidade. Diz o autor: «O "dom da escuta" assenta precisamente na capacidade de prestar uma atenção profunda e contemplativa [ao que nos rodeia e em nós habita, digo eu], capacidade vedada ao ego hiperactivo dos nossos dias» (Han, 2010: 27).

Diz ainda o autor sul-coreano que «[o] cansaço associado ao esgotamento é um cansaço de potência positiva. Torna o homem incapaz de fazer alguma coisa. O cansaço inspirador é um cansaço da potência negativa, ou seja, do não-fazer» (Han, 2010: 55), a que eu acrescento: porque para isso é necessário sentir o compassamento de cada respiração. 


\section{REFERÊNCIAS BIBLIOGRÁFICAS}

H AN, Byung-Chul (2010), A Sociedade do Cansaço, Lisboa, Relógio D’Água Editores.

- (2012), A Agonia de Eros, Lisboa, Relógio D’Água Editores.

JELINEK, Elfriede (2012), Der Tod und das Mädchen I- V Prinzessinnendramen, Berlim, Bloomsbury Verlag.

MENDEs, Anabela (2015), A Morte e a Donzela I - V Dramas de Princesas, dactiloscrito, tradução do alemão, Lisboa, Associação Artes \& Engenhos.

MOLDER, Maria Filomena (2003), A Imperfeição da Filosofia, Lisboa, Relógio D’Água Editores.

Murcho, Desidério (2006), Pensar Outra Vez-Filosofia, Valor e Verdade, Vila Nova de Famalicão, Quasi Editores.

\section{ANABELA MENDES}

Anabela Mendes (1951) é professora na Faculdade de Letras da Universidade de Lisboa e investigadora sénior do CECC - Centro de Estudos de Comunicação e Cultura da Universidade Católica Portuguesa. Desenvolve a sua actividade científica e ensaística nas áreas da Germanística, Estética e Filosofia da Arte, Ciência e Arte, Teoria e Dramaturgia Radiofónica, Artes Performativas, Viagens de Longo Curso. Integra actualmente um grupo de trabalho sobre o tema Pensar a Medicina, sediado no Hospital de Santa Maria. Desenvolveu com outros colaboradores, ao longo de três anos, um projecto agora em edição dedicado a Teatro e Tribunal. A sua publicação mais recente é Viagens de Longo Curso: Roteiros e Mapeações (Lisboa, UniEditora, UCP, 2016). 